\title{
Estimation of optimum specific light intensity per cell on a high-cell-density continuous culture of Chlorella zofingiensis not limited by nutrients or $\mathrm{CO} 2$
}

\begin{abstract}
To determine the optimum light intensity per cell required for rapid growth regardless of cell density, continuous cultures of the microalga Chlorella zofingiensis were grown with a sufficient supply of nutrients and $\mathrm{CO} 2$ and were subjected to different light intensities in the range of $75 \ddot{1} 1000$ EE mī 2 sī 1 . The cell density of culture increased over time for all light conditions except for the early stage of the high light condition of 1000 EE mī 2 sī 1. The light intensity per cell required for the high specific growth rate of 0.5 daȳ 1 was determined to be $28 і ̈ 45$ EE g-dsī 1 sī 1 . The specific growth rate was significantly correlated to light intensity $(\mathrm{y}=0.721 \times \mathrm{x} /(66.98+\mathrm{x}), \mathrm{r} 2=0.85, \mathrm{p}<0.05)$. A high specific growth rate was maintained over a range of light intensities (250ї 1000 EE mī 2 sī 1). This range of light intensities suggested that effective production of $\mathrm{C}$. zofingiensis can be maintained outdoors under strong light by using the optimum specific light intensity.
\end{abstract}

Keyword: Biomass production of microalgae; Chlorella zofingiensis; High-cell-density culture; Nutrient and CO2 supply; Optimum light condition 